6. Shea, J. \& Brooks, C. L. From folding theories to folding proteins: a review and assessment of simulation studies of protein folding and unfolding. Annu. Rev. Phys. Chem. 52, 499-535 (2001).

7. Ferrara, P., Apostolakis, J. \& Caflisch, A. Thermodynamics and kinetics of folding of two model peptides investigated by molecular dynamics simulations. J. Phys. Chem. B 104, 5000-5010 (2000).

8. Daura, X., Jaun, B., Seebach, D., Gunsteren, W. F. v. \& Mark, A. E. Reversible peptide folding in solution by molecular dynamics simulation. J. Mol. Biol. 280, 925-932 (1998).

9. Ferrara, P. \& Caflisch, A. Folding simulations of a three-stranded antiparallel $\beta$-sheet peptide. Proc Natl Acad. Sci. USA 97, 10780-10785 (2000).

10. Zagrovic, B., Sorin, E. J. \& Pande, V. S. $\beta$-hairpin folding simulations in atomistic detail using an implicit solvent model. J. Mol. Biol. 313, 151-169 (2001).

11. Fersht, A. R., Matouschek, A. \& Serrano, L. The folding of an enzyme I. Theory of protein engineering analysis of stability and pathway of protein folding. J. Mol. Biol. 224, 771-782 (1992).

12. Lapidus, L. J., Eaton, W. A. \& Hofrichter, J. Measuring the rate of intramolecular contact formation in polypeptides. Proc. Natl Acad. Sci. USA 97, 7220-7225 (2000).

13. Bieri, O. et al. The speed limit of protein folding measure by triplet-triplet energy transfer. Proc. Nat Acad Sci. USA 96, 9597-9601 (1999).

14. Shirts, M. \& Pande, V. S. Screen savers of the world unite. Science 290, 1903-1904 (2000).

15. Struthers, M., Ottesen, J. J. \& Imperiali, B. Design and NMR analyses of compact, independently folded BBA motifs. Folding Des. 3, 95-103 (1998).

16. Struthers, M. D., Cheng, R. C. \& Imperiali, B. Design of a monomeric 23-residue polypeptide with defined tertiary structure. Science 271, 342-345 (1996).

17. Ervin, J., Sabelko, J. \& Gruebele, M. Submicrosecond real-time fluorescence detection: application to protein folding. J. Photochem. Photobiol. Biol. 54, 1-15 (2000).

18. Chandler, D. Statistical mechanics of isomerization dynamics in liquids and the transition state approximation. J. Chem. Phys. 68, 2959-2970 (1978).

19. Gilmanshin, R., Williams, S., Callender, R. H., Woodruff, W. H. \& Dyer, R. B. Fast events in protein folding: relaxation dynamics of secondary and tertiary structure in native apomyoglobin. Proc. Nat Acad. Sci. USA 94, 3709-3713 (1997).

20. Ballew, R. M., Sabelko, J. \& Gruebele, M. Direct observation of fast protein folding: the initial collapse of apomyoglobin. Proc. Natl Acad. Sci. USA 93, 5759-5764 (1996).

21. Plaxco, K. W., Simons, K. T. \& Baker, D. Contact order transition state placement and the refolding rates of single domain proteins. J. Mol. Biol. 277, 985-994 (1998).

22. Moore, S. \& Stein, W. Amino acid determination, methods and techniques. J. Biol. Chem. 192 663-670 (1951).

23. Ponder, J. W. \& Richards, F. M. An efficient Newton-like method for molecular mechanics energy minimization of large molecules. J. Comput. Chem. 8, 1016-1024 (1987).

24. Fletcher, R. \& Powell, M. J. D. A rapidly convergent descent method for minimization. Comput. J. 6, $163-168$ (1963)

25. Koehl, P. \& Delarue, M. On the use of a self-consistent mean field theory to predict protein side chain conformations and estimate their entropies. J. Mol. Biol. 239, 249-275 (1994).

26. Qiu, D., Shenkin, P. S., Hollinger, F. P. \& Still, W. C. The GB/SA Continuum model for solvation. A fast analytical method for the calculation of approximate Born radii. J. Phys. Chem. A 101, 3005-3014 (1997).

27. Jorgensen, W. L. \& Tirado-Rives, J. The OPLS force field for proteins. Energy minimizations for crystals of cyclic peptides and crambin. J. Am. Chem. Soc. 110, 1657-1666 (1988)

28. Andersen, H. C. Rattle: a 'velocity' version of the shake algorithm for molecular dynamics colculations. J. Comput. Phys. 52, 24-34 (1983).

29. Kabsch, W. \& Sander, C. Dictionary of protein secondary structure: pattern recognition of hydrogen bonded and geometrical features. Biopolymers 22, 2577-2637 (1983).

Supplementary Information accompanies the paper on Nature's website ( http://www.nature.com/nature)

Acknowledgements We thank the Folding@Home volunteers whose processor power made this work possible; the members of the Pande, Levitt and Gruebele laboratories for discussion; J. Ottesen for the BBA5 coordinates; B. Imperiali for NMR data; the UIUC Laboratory for Fluorescence Dynamics; and the Suslick group for equipment use. C.S. was supported by a predoctoral Howard Hughes Medical Institute fellowship. V.P. and the Folding@Home project were supported by the National Institutes of Health (NIH), American Chemical Society-Petroleum Research Fund, National Science Foundation Materials Research Science \& Engineering Centers, Center on Polymer Interfaces and Macromolecular Assemblies seed funds, and a gift from Intel. H.N. was supported by an NIH biophysics training grant. H.N. and M.G. were also funded by the NIH.

Competing interests statement The authors declare that they have no competing financial interests.

Correspondence and requests for materials should be addressed to V.S.P. (e-mail: pande@stanford.edu) or M.G. (e-mail: gruebele@scs.uiuc.edu). erratum

\section{Simulation of the atmospheric thermal circulation of a martian volcano using a mesoscale numerical model}

\section{Scot C. R. Rafkin, Magdalena R. V. Sta. Maria \& Timothy I. Michaels}

Nature 419, 697-699 (2002).

In this Letter, "(see Supplementary Information)" should have appeared at the end of the third sentence of the third paragraph. At the end of the Letter, the line "Supplementary Information accompanies the paper on Nature's website ( http://www.nature.com/ nature)." should have been included.

\section{corrigendum}

\section{Undermethylation associated with retroelement activation and chromosome remodelling in an interspecific mammalian hybrid}

Rachel J. Waugh O'Neill, Michael J. O'Neill \& Jennifer A. Marshall Graves

Nature 393, 68-72 (1998).

In this Letter, the maternal species listed for hybrid BE-1 is attributed to Macropus engenii. However, our ongoing studies show that the maternal complement of chromosomes in BE-1 was inherited from a Macropus rufogriseus female. The centromeres of $M$. rufogriseus chromosomes are extended in comparison to all other macropod species. The extent, therefore, to which the centromere extensions shown in Fig. 4 can be attributed to hybridspecific amplification of the retrolement KERV-1 cannot be precisely determined. Nevertheless, Southern analysis confirms that this retroelement is present at a $20 \%$ higher copy number in the hybrid's genome compared with that of its parents, and FISH analysis shows KERV-1 localization only to centromeres in the hybrid. Our conclusions regarding hybrid-specific undermethylation in this hybrid individual are not affected because $M$. rufogriseus shows methylation levels typical of species within the macropod group. Hybrid-specific undermethylation and genome rearrangement also remain true for the Petrogale hybrids we presented. 